\title{
ABSOLUTE CONTINUITY OF MINIMAL UNITARY DILATIONS
}

\author{
MAREK KOSIEK
}

Abstract. The paper considers the question of absolute continuity of minimal unitary dilation of an absolutely continuous pair of commuting Hilbert space contractions. More general result covering commuting $\mathrm{N}$-tuples, operator representations and their minimal dilations is given.

Mathematics subject classification (2000): Primary: 47A20; Secondary: 47A60, 46J10, 46E25. Keywords and phrases: contractions, dilations, representations, absolute continuity, decompositions.

\section{REFERENCES}

[1] T. Ando, On a pair of commutative contractions, Acta Sci. Math. (Szeged), 24 (1963), 88-90.

[2] C. Apostol, Functional calculus and invariant subspaces, J. Operator Theory, 4 (1980), 159-190.

[3] H. Bercovici And W. S. Li, Isometric Functional Calculus on the Bidisk, Bull. London Math. Soc., 25 (1993), 582-590.

[4] B. J. Cole And T. W. GAmelin, Tight uniform algebras of analytic functions, J. of Funct. Anal., 46 (1982), 158-220.

[5] J. B. Conway, The theory of subnormal operators, American Mathematical Society, Providence, Rhode Island, 1991.

[6] M. Kosiek, Representation generated by a finite number of Hilbert space operators, Ann. Polon. Math., 44 (1984), 309-315.

[7] Unitary dilations of contractive representations of $H^{\infty}\left(\mathbb{D}^{N}\right)$, Contemporary Mathematics, 189 (1995), 369-371.

[8] _ Functional calculus and common invariant subspaces, Wydawnictwo Uniwersytetu Jagiellońskiego 2001, Rozprawy Habilitacyjne Uniwersytetu Jagiellońskiego Nr 353.

[9] _ Fuglede-type decompositions of representations, Studia Math., 151, 1 (2002), 87-98.

[10] M. KosieK And A. Octavio, Representations of $H^{\infty}\left(\mathbb{D}^{N}\right)$ and absolute continuity for $N$-tuples of contractions, Houston J. Math., 30, 3 (1997), 529-537.

[11] Wold-type extensions for $N$-tuples of commuting contractions, Studia Math., 137, 1 (1999), $81-91$.

[12] On common invariant subspaces for commuting contractions with rich spectrum, Indiana Univ. Math. J., 53, 3 (2004), 823-844.

[13] W. MLaK, Decompositions and extensions of operator valued representations of function algebras, Acta Sci. Math. (Szeged), 30 (1969), 181-193.

[14] F. H. SZAFRANIEC, Decompositions of non-contractive operator-valued representations of Banach algebras, Studia math., 42 (1972), 97-108. 